\title{
Uncoupling of atrial natriuretic peptide and cyclic guanosine 3',5'-monophosphate production in patients with liver cirrhosis
}

\author{
K.-P. Vorderwinkler ${ }^{1}$, G. Jakob ${ }^{1}$, J. Mair ${ }^{1}$, G. Judmaier ${ }^{2}$, B. Puschendorf ${ }^{1}$ \\ ${ }^{1}$ Institut für Medizinische Chemie und Biochemie, Universität Innsbruck, Fritz-Pregl-Strasse 3, A-6020 Innsbruck, Austria \\ ${ }^{2}$ Klinik für Innere Medizin, Universität Innsbruck, Anichstrasse 35, A-6020 Innsbruck, Austria
}

Received: 9 July 1993 / Accepted: 5 October 1993

Atrial natriuretic peptide (ANP) concentrations within the reference interval have been reported in patients with alcoholic liver disease, chronic active hepatitis, and hepatocellular carcinoma. Markedly increased ANP concentrations, by contrast, have been found in patients with liver cirrhosis [3]. Exogenously administered ANP has been found to elevate the plasma concentration of its second messenger cyclic guanosine monophosphate (cGMP) in accordance with its physiological effects [4] Therefore, cGMP increase in plasma can be regarded as a marker for the biological activities of ANP. Because of contradictory reports $[2,3,5]$ on ANP in liver cirrhosis we investigated plasma ANP and cGMP concentrations to assess the biological activity of ANP in liver cirrhosis.

Plasma ANP concentrations were determined in 124 healthy volunteers ( 72 males, 52 females) aged 20-64 years $(40 \pm 12$ years) and plasma cGMP concentrations in 147 healthy blood donors ( 92 males, 55 females) aged $15-62$ years $(34 \pm 13$ years). Plasma ANP and cGMP concentrations were determined in 15 patients with liver cirrhosis ( 7 males, 8 females) aged $31-69$ years $(54 \pm 14$ years). Five patients had ascites. The underlying cause of cirrhosis was $\alpha_{1}$-antitrypsin deficiency in 4 patients, alcohol abuse in 7 , chronic hepatitis in 2 , and unknown in 2. Creatinine concentrations in plasma were within the normal range $(79.56 \pm 9.547 \mu \mathrm{mol} / 1$, range: $66.3-101.66 \mu \mathrm{mol} / \mathrm{l})$ in all patients.

Plasma cGMP concentrations were determined by radioimmunoassay (Amersham International, Amersham, Buckinghamshire, UK), and ANP concentrations in plasma were measured by means of a commercially available radioimmunoassay (Eiken, Tokyo, Japan) without extraction [1]. Results are expressed as mean $\pm \mathrm{SD}$. Groups were compared statistically using Mann-Whitney $U$ test; significance was defined as $P<0.05$.

Plasma cGMP concentrations in patients with liver cirrhosis $(4.448 \pm 2.022 \mathrm{nmol} / 1$, range $0.5-8.28 \mathrm{nmol} / 1, n=15)$ did not differ significantly from those in healthy controls $(4.637 \pm$ $1.533 \mathrm{nmol} / 1$, range, $1.88-9.04 \mathrm{nmol} / 1, \quad n=147, \quad P=0.9426$; Fig. 1). By contrast, plasma ANP concentrations were significantly higher in patients with cirrhosis $(213.867 \pm 83.032 \mathrm{ng} / 1$, range $107-389 \mathrm{ng} / 1, n=15)$ than in healthy controls $(69.5 \pm$ $26.05 \mathrm{ng} / 1$, range $18-151 \mathrm{ng} / 1, n=124, P=0.0001$; Fig. 1$)$. In the group of patients with liver cirrhosis no significant difference in plasma ANP $(206.2 \pm 59.437$ versus $217.7 \pm 95.422, P=1)$ or plasma cGMP $(5.656 \pm 1.804$ versus $3.777 \pm 1.897, P=0.142)$ concentrations were detectable between patients with and patients without ascites.

We found increased immunoreactive ANP concentrations without a concomitant increase in plasma cGMP in our patients with liver cirrhosis. In accordance with earlier reports we found no significant difference in plasma concentrations of ANP [3]

Abbreviations: $\mathrm{ANP}=$ atrial natriuretic peptide; $\mathrm{cGMP}=$ cyclic guanosine monophosphate

Correspondence to: $\mathrm{B}$. Puschendorf

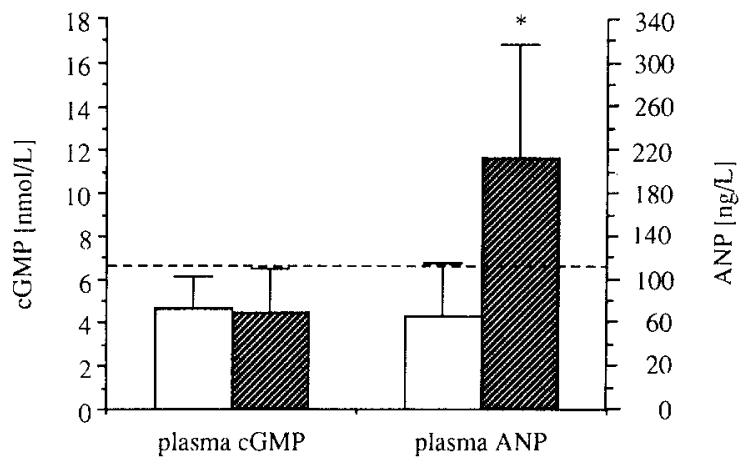

Fig. 1.ANP and cGMP plasma concentrations in healthy controls and in patients with liver cirrhosis. Broken line, upper limit of the reference values of cGMP (6.6 nmol/l) and ANP (112 ng/l) plasma concentrations. Asterisk, significant difference from controls. $\square$ Control; $\square$ cirrhosis

between cirrhotic patients with and without ascites. cGMP plasma concentrations were also not significantly different between cirrhotic patients with and without ascites. Low cGMP plasma concentrations in the presence of high levels of immunoreactive ANP indicate a reduced biological activity of ANP in liver cirrhosis. A possible explanation is an impaired degradation of ANP by the cirrhotic liver [3] together with a down-regulation of ANP receptors [4]. Our results, however, are also in accordance with an incomplete enzymatic processing of precursor ANP in liver cirrhosis [2], which may also lead to a mismatch between immunoreactive and biological active ANP.

\section{References}

1. Fridrich L, Szekeres T, Hartter E, Schweighofer F, Gassner A, Laczkovic A (1989) Correlation between heart disorders and concentrations of directly measured atrial natriuretic peptide in plasma. Clin Chem 35:435-439

2. Gerbes AL, Arendt RM, Zähringer J, Paumgartner G (1986) Atrial natriuretic peptide, the sympathetic nervous system, and decompensated cirrhosis. Lancet I: 331

3. Kawasaki H, Uemasu J, Maeda N, Hirayama C, Kobayashi T, Sakurai H (1987) Plasma levels of atrial natriuretic peptide in patients with chronic liver disease. Am J Gastroenterol $82: 727-731$

4. Tsutamoto T, Kanamori T, Wada A, Kinoshita M (1992) Uncoupling of atrial natriuretic peptide extraction and cyclic guanosine monophosphate production in the pulmonary circulation in patients with severe heart failure. J Am Coll Cardiol 20:541-546

5. Wernze H, Burghardt W (1986) Atrial natriuretic peptide, the sympathetic nervous system, and decompensated cirrhosis. Lancet I: 331 